\title{
Letters
}

Website: bmj.com

Email: letters@bmj.com

\section{Concerns about immunisation}

\section{Breast feeding should be promoted}

EDITOR-Bedford and Elliman make some important statements about immunisation. ${ }^{1}$ Certainly, millions of lives have been saved. Smallpox has been eradicated, and polio should be eradicated soon. But are routine vaccines safe? Four months after the Centers for Disease Control and Prevention in the United States recommended that all babies should receive three doses of the rotavirus vaccine, the use of this vaccine was being indefinitely suspended after reports of over 100 cases of intussusception and two deaths resulting from its use. ${ }^{2}$ The manufacturer voluntarily withdrew the vaccine.

In July 1999 the US Public Health Service and the American Academy of Pediatrics asked vaccine manufacturers to eliminate the preservative mercury from vaccines because of concern about its cumulative effects. ${ }^{3}$ Babies who receive the 15 recommended vaccines in the first six months of their lives have a cumulative mercury exposure that exceeds limits set by the Environmental Protection Agency. What is the impact when, by the age of 5 years, children have received over two dozen doses of vaccines containing mercury and other toxins?

Some scientists say that the massive polio immunisation campaign in Zaire and other African countries in the 1950s accelerated the spread of HIV. ${ }^{4}$ The aerosol vaccine was grown in monkey kidney tissue; that same species of monkey carries a simian immune deficiency virus. The places where the vaccine was administered are the epicentre of the AIDS epidemic. Was the vaccine the vector that carried the immune deficiency virus to humans? The answers to this most important question are inconclusive and controversial.

It costs millions to develop, research, and market a vaccine. Wouldn't it make more sense to spend that money to protect, promote, and support breast feeding for every baby? There is much evidence that breast feeding reduces the incidence and severity of rotavirus, respiratory syncytial virus, and otitis media, without side effects. ${ }^{5}$

There can be conflict when economic and political interests enter the realm of public health. We have seen how important information about safety has been hidden to protect profit; the tobacco industry lawsuits are an illustration. We have seen it when the sons and daughters of the mothers who were given diethylstilbestrol showed up seriously ill a generation later, and when infants whose mothers were given thalidomide were born deformed. How long must a clinical trial be to ensure safety? One generation? Two? More?

Nikki Lee faculty member

Center for Breastfeeding, 8 Jan Sebastian Way, Number 13, Sandwich, MA 02563, USA

Competing interests: None declared

1 Bedford H, Elliman D. Concerns about immunisation. $B M$ 2000;320:240-3. (22 January.)

CDC Withdrawal of rotavirus vaccine recommendation. JAMA 1999;282:2113-4.

3 Miller JL. Elimination of thimerosal from vaccines set as goal. Am J Health Syst Pharm 1999 Aug 15;56:1589, 1593.

4 Stricker RB, Elswood BF. Polio vaccines and the origin of Stricker RB, Elswood BF. Polio vaccines and
AIDS: an update. Med Hypotheses 1997;48:193.

AIDS: an update. Med Hypotheses 1997;48:193.
5 Grover M, Giouzeppos O, Schnagl RD, May JT. Effect of 5 Grover M, Giouzeppos O, Schnagl RD, May JT. Effect of
human milk prostaglandins and lactoferrin and respiratory syncytial virus and rotavirus. Acta Paediat tory syncytial

\section{Is vaccination cause célèbre or bête noire?}

EDITOR-Bedford and Elliman discuss some of the concerns about immunisation. ${ }^{1}$ The Faculty of Homoeopathy speaks for a medically qualified minority. The more numerous medically unqualified homoeopaths belong to the Society of Homoeopaths, the Institute of Complementary Medicine, or the Homoeopathic Medical Association, totalling some 2000 practitioners. None of these bodies supports vaccination. The Society of Homoeopaths, in a leaflet, encouraged parents to seek advice about it. Currently the Homoeopathic Medical Association has no policy on vaccination. The Institute of Complementary Medicine, which has a register of "classical homoeopaths," opposes vaccination.

Homoeopaths' views derive more from leading writers than professional bodies. James Compton Burnett discovered vaccine damage in the $1880 \mathrm{~s}$, and Stuart Close denounces all mass treatments as fundamentally unholistic. Harris Coulter, a historian, blames vaccination for mental illness, crime, and social deviance. A prominent Dutch homoeopath describes "post vaccination syndrome," and he claims that potentised vaccines can cure this syndrome and act prophylactically against many infections. This claim was confirmed by Margery Grace Blackie, the Queen's former physician. ${ }^{2}$

Martin Miles, a London homoeopath, extends Coulter's views, claiming that vaccination causes cancer, meningitis, arthritis, constitutional weaknesses and neurological damage, and increases the level of mucus in the body. A leading homoeopath, George Vithoulkas, thinks that vaccination ignores the susceptibility of individual patients, is fundamentally unhomoeopathic, and leads to the degeneration of whole populations' health. None of them supports vaccination: the original article and the faculty stand alone. From about 1903 until the 1970s, even the faculty endorsed an approach that regarded bacteria as harmless scavengers and opposed vaccination. ${ }^{2}$

The data presented by Bedford and Elliman do not conclusively show that vaccination caused the decline of infectious diseases. Diphtheria, tuberculosis, and pertussis were virtually extinct before vaccines were introduced. American and British data show similar patterns. More likely causes are improved water supply, sanitation, adequate food supply, and birth control. Many were declining before the immunisation programmes began. ${ }^{4}$ I therefore remain unconvinced and agree with Stacey's assessment that the decline of many infectious diseases is or was as much due to improved sanitation as to anything else--including immunisations. ${ }^{5}$

Peter Morrell honorary research associate, history of medicine

Department of Sociology, Staffordshire University, Stoke-on-Trent ST4 2DE peter.morrell@tesco.net

Competing interests: None declared.

\section{Advice to authors}

We prefer to receive all responses electronically, sent either directly to our website or to the editorial office as email or on a disk. Processing your letter will be delayed unless it arrives in an electronic form.

We are now posting all direct submissions to our website within 24 hours of receipt and our intention is to post all other electronic submissions there as well. All responses will be eligible for publication in the paper journal.

Responses should be under 400 words and relate to articles published in the preceding month. They should include $\leqslant 5$ references, in the Vancouver style, including one to the BMJ article to which they relate. We welcome illustrations.

Please supply each author's current appointment and full address, and a phone or fax number or email address for the corresponding author. We ask authors to declare any competing interest. Please send a stamped addressed envelope if you would like to know whether your letter has been accepted or rejected.

Letters will be edited and may be shortened.

bmj.com

letters@bmj.com 
1 Bedford H, Elliman D. Concerns about immunisation. BMJ 2000;320:240-3. (22 January.)

2 Winston J. The faces of homeopathy: a history of the first 200 years. Wellington, New Zealand: Great Auk Publishing, 1999.

3 Miles M. Homeopathy and human evolution. London: Winter Press, 1992.

4 Leavitt J, Numbers R. Sickness and health in America. Madison, WI: University of Wisconsin, 1978.

5 Stacey M. The sociology of health and healing. London: Unwin, 1988

\section{Facts are not enough}

EDITOR-Bedford and Elliman provide a useful summary of the main evidence supporting the safety and effectiveness of vaccines. ${ }^{1}$ They suggest that their evidence based refutations of erroneous beliefs commonly expressed by immunisation defaulters are useful in dispelling their concerns. This assumes that those who express these beliefs are simply mistaken and when exposed to counter-arguments will realise this.

Although we believe that it will always be important for scientists and health professionals to refute misleading information, there is little empirical support for the hope that decision making about vaccination is based on "facts" alone. In their research on cognitive processes in vaccination decision making, Meszaros et al showed that when parents opposed to the vaccine for diphtheria, tuberculosis, and pertussis were presented with factual information about risks and benefits they became more committed to their antipathetic position. This response was moderated by underlying values about death and chronic disability.

Our own research on antivaccination press reportage has shown that manifest claims about vaccines being dangerous and ineffective tend to be located under a canopy of more general discourses about cover up and conspiracy, manipulation by venal private enterprise interests, governments with totalitarian agendas, and the back to nature idyll. ${ }^{3}$ We argue that what generates the appeal of antivaccination claims is underlying reference to these wider issues. We are now undertaking qualitative research with parents and immunisation providers in an attempt to explore the nature of the appeal of both anti-immunisation rhetoric and reassurances by providers. Although this work is incomplete, we have been impressed by how frequently parents in focus group discussions are adamant that they want to be given the "facts" but demonstrate minimal retention of these when exposed to television items containing pro-immunisation and anti-immunisation claims. What is retained and discussed and prompts strong responses from participants are images of children who have allegedly been damaged by vaccines. In other words, the facts have little potency when competing with the very emotive news stories found in the media.

Any attempt at refuting or deflating the persuasive power of vaccination arguments must address the potential gut level appeal at which anti-immunisation rhetoric tends to operate. What we have learnt about immunisation science will be of no public value ultimately if we ignore key lessons from health communication science.

Julie-Anne Leask research officer

Simon Chapman associate professor

Penelope Hawe senior lecturer

Department of Public Health and Community Medicine, University of Sydney, Sydney NSW,

Australia

Competing interests: Dr Leask and Professor Chapman have been reimbursed for attending a conference and have received funds for research from CSL Vaccines.

Bedford H, Elliman D. Concerns about immunisation. $B M$ 2000;320:240-3. (22 January.)

2 Meszaros JR, Asch DA, Baron J, Hershey JC, Kunreuthe $\mathrm{H}$, Schwartz-Buzaglo J. Cognitive processes and the decisions of some parents to forego pertussis vaccination for their children. J Clin Epidemiol 1996;49:697-703.

3 . the

Leask J-A, Chapman S. An attempt to swindle nature':

Public Health 1998;22:17-26.

\section{Authors' reply}

EDITOR-We welcome the interest taken in our article as we believe immunisation to be very important. Lee concedes that vaccines have been an important health initiative but questions their safety. She rightly points out that rotavirus vaccine was withdrawn after being in use in the United States for less than a year. This is in fact an excellent example of how closely the safety of vaccines is monitored. As soon as there was serious suspicion of a problem, the vaccine was suspended from use and an extensive investigation conducted. When the results of this were announced, the vaccine was permanently withdrawn.

Lee also cites other examples of the possible side effects of vaccines. There is no evidence that anyone has come to harm from the mercury in vaccines, but it seems reasonable to eliminate any potential risk, however small. For this reason, many governments have urged vaccine manufacturers to eliminate mercury from vaccines as soon as is practicable. There is no convincing scientific evidence that polio vaccines in Africa had anything to do with the origin or spread of AIDS.

Morrell points out that many homoeopaths advise their clients to avoid conventional vaccines. We were trying to make the point that the common assumption that homoeopathy and orthodox immunisation are incompatible is a myth, a view by which we stand. We do not claim that the only explanation for the fall in the incidence of many diseases is the introduction of vaccination. There is, however, overwhelming evidence of the efficacy of vaccines, both from trials conducted before their widespread introduction and from experience of groups who remain unimmunised when most of the population has accepted vaccine. Outbreaks of disease among communities that reject immunisation have caused not only disease but also death, most recently in an epidemic of measles in the Netherlands.

Leask et al make a fair point, which we accept. There are many interrelated factors that determine whether or not children are immunised. Parents' attitudes to the safety and efficacy of vaccines and the severity of disease are among the most important determinants of vaccine uptake. ${ }^{3}$ We need to look no further for evidence of this than the recent decline in uptake of measles, mumps, and rubella vaccine in the United Kingdom, which has followed much publicised claims that the vaccine is linked with autism. Although we recognise that knowledge alone does not change behaviour, there are many myths circulating about immunisation and infectious diseases, and without accurate information it is not possible to make a fully informed decision. The other aspects mentioned by Leask et al are more intangible and may reflect the empathy between parent and professional. ${ }^{4}$ Even that relationship will be influenced in turn by an individual's wider perceptions of governments and industry.

Helen Bedford senior research fellow Department of Epidemiology and Public Health, Institute of Child Health, London WC1N 1EH

David Elliman consultant in community child health St George's Hospital, London SW17 0QT

Competing interests: Dr Bedford and Dr Elliman have both been sponsored to attend and speak at educational meetings and have conducted research funded by manufacturers of vaccines.

1 Centers for Disease Control and Prevention. Withdrawal of rotavirus vaccine. http://www.cdc.gov/epo/mmwr/ of row vaccine. http://www.cdc.gov/epo/nnw ary 2000).

2 Communicable Disease Surveillance Centre. Outbreaks of measles in communities with low vaccine coverage. Commun Dis Rep CDR Weekly 2000;10:29,32.

3 Peckham C, Bedford H, Senturia Y, Ades A. National imm nisation study:factors influencing immunisation uptake in childhood. Horsham: Action Research, 1989

4 Harrington PM, Woodman C, Shannon WF. Low immunisation uptake: is the process the problem? J Epidemiol Community Health 2000;54:394-400.

\section{Hyperbaric oxygen in carbon monoxide poisoning}

\section{Authors of study clarify points that they made}

EDitor-We would like to clarify some of the statements that Weaver made about our double blind randomised trial of hyperbaric compared with normobaric oxygen treatment of carbon monoxide poisoning. ${ }^{12}$ Weaver expresses concern that concomitant depression and use of psychoactive drugs might have influenced the results, given the large percentage of suicide attempts in our cohort of patients. Depression and the use of drugs may indeed have resulted in a higher incidence of poor outcome overall, but this would not have biased the comparison between normobaric and hyperbaric groups: patients were specifically stratified for attempted suicide before randomisation to treatment.

Weaver seems to be concerned about the delay in receiving hyperbaric oxygen treatment. Although the geometric mean treatment delay was 7.1 hours, we performed subgroup analysis of patients treated within four hours (all patients, and severely poisoned patients alone). We also analysed outcome in four groups according 
to time to treatment $(<3,3-60,6-12,>12$ hours) and found no difference in outcome between hyperbaric and normobaric oxygen groups. Further multivariable analysis did not identify delay in treatment as a predictor of poor outcome. Thus there was no evidence that delay to treatment might have explained the lack of benefit of hyperbaric oxygen.

Weaver also questions our use of cluster randomisation. With this we allocated more than one person simultaneously to the same treatment on 22 occasions (two on 12 occasions, three on five occasions, and four on five occasions). Overall, 14 clusters (40 patients) were allocated to hyperbaric oxygen and eight clusters (19 patients) to normobaric oxygen. Continuous outcome variables were analysed by the mixed procedures in SAS, which allows a repeated measures analysis of variance, with the variable cluster being treated as a random repeated measurement, thus adjusting for within cluster variation. ${ }^{3}$

We also repeated the analysis excluding all patients who were allocated as part of a cluster and further repeated it adjusting for the three variables (exposure time, time to carboxyhaemoglobin measurement, and time to treatment) that uniquely defined the cluster. These analyses suggest that our results were not biased by cluster randomisation.

Weaver refers to Thom et al's findings of no relapses in their patients given hyperbaric oxygen, but it is important to note that all five relapses in our study occurred in patients given hyperbaric oxygen $(\mathrm{P}=0.03)$.

C D Scheinkestel deputy director

cdsch@ozemail.com.au

D V Tuxen director

Department of Intensive Care and Hyperbaric Medicine, Alfred Hospital, Melbourne, Australia

M Bailey statistical consultant

Department of Epidemiology and Preventive

Medicine, Monash University, Melbourne

P S Myles head of research

Department of Anaesthesia and Pain Management, Alfred Hospital, Melbourne

K Jones psychologist

School of Psychology, La Trobe University,

Melbourne, Australia

D J Cooper head of trauma intensive care unit Alfred Hospital, Melbourne

I L Millar head of hyperbaric medicine

Alfred Hospital, Melbourne

1 Weaver LK. Hyperbaric oxygen in carbon monoxide poisoning. BMJ 1999:319:1083-4. (23 October.)

2 Scheinkestel CD, Bailey M, Myles PS, Jones K, Cooper DJ, Millar IL, et al. Hyperbaric or normobaric oxygen for acute Millar IL, et al. Hyperbaric or normobaric oxygen for acute
carbon monoxide poisoning: a randomised controlled carbon monoxide poisoning: a rando

3 Littell RC, Milliken GA, Stroup WW, Wolfinger RD. SAS (computer program). Version 6.12. Cary, NC: SAS Institute, 1996.

\section{$100 \%$ oxygen is best option}

EDITOR-Weaver presents a well balanced editorial on the controversy surrounding the treatment of carbon monoxide poisoning with hyperbaric oxygen. ${ }^{1}$ This is refreshing, as a previous editorial in the $B M J$ was not so objective. ${ }^{2}$

Weaver mentions four prospective randomised studies of normobaric versus hyperbaric oxygen. The latest of these is the most convincing, being prospective, randomised, and double blind, with sham hyperbaric treatments. ${ }^{3}$ Weaver is critical of the use of continuous high oxygen concentrations for three days in the control group because this was not representative of usual practice. Previous studies have been flawed by a failure to optimise treatment in the normobaric group, and Scheinkestel et al's study clearly shows that such cheap, available, safe treatment is also effective. The claim that optimal normobaric oxygen treatment is not in routine use for this condition is cause for considerable concern.

Weaver also criticises Scheinkestel et al for not applying hyperbaric oxygen earlier in their study. This criticism comes despite the lack of evidence from controlled prospective comparative studies that earlier treatment is any more beneficial and despite the fact that subgroup analysis of treatment within four hours showed no benefit from hyperbaric oxygen. Scheinkestel et al's study is representative of most clinical practice because of late presentation and the need for stabilisation and transport to a remote hyperbaric facility.

Scheinkestel et al's study has shown that hyperbaric oxygen results in a worse outcome than does normobaric treatment Even if it is wrong, the degree of any benefit is unlikely to be clinically importan compared with the risk of such treatment. Hyperbaric oxygen and the associated transportation are associated with appreciable hazards to both the attendant and the patient, which are often understated. I therefore suggest that the multicentre study that Weaver proposes would now be unethical.

In carbon monoxide poisoning 100\% oxygen should be given immediately and continued for several days. Resources should be concentrated on promulgating this message together with preventing carbon monoxide poisoning and detecting it early rather than on providing more hyperbaric oxygen facilities. The NHS and healthcare agencies in the United States should review their funding strategy for the use of hyperbaric oxygen in acute carbon monoxide poisoning, because the only benefit would seem to be towards the profitability of independent hyperbaric facilities.

S Q M Tighe consultant anaesthetist

Countess of Chester Hospital NHS Trust, Chester CH2 1UL

Sean_Tighe@msn.com 1 Weaver LK. Hyperbaric oxygen in carbon monoxide
poisoning. BMJ 1999;319:1083-4. (23 October.)
2 Kindwall EP. Hyperbaric oxygen. BMJ 1993;307:515-6.
3 Scheinkestel CD, Bailey M, Myles PS, Jones K, Cooper DJ,
Millar IL, et al. Hyperbaric or normobaric oxygen for acute
carbon monoxide poisoning: a randomised controlled
clinical trial. Med JAust 1999;170:203-10.

\section{Author's reply}

EDITOR-Scheinkestel et al clarify the issues regarding concomitant depression, delay to hyperbaric oxygen, and cluster randomisation in their clinical trial. ${ }^{1}$ I agree that attempted suicide probably did not bias the outcome between the two arms. ${ }^{2}$ The data provided strengthen the inferences from their trial.

Thom et al found no delayed neuropsychological sequelae in their patients given hyperbaric oxygen, ${ }^{3}$ whereas Scheinkestel et al found relapses only in patients given this treatment. Clearly the evidence regarding the effectiveness of hyperbaric oxygen in carbon monoxide poisoning remains conflicting.

In the United States the commonest treatment for acute carbon monoxide poisoning is inhalation of oxygen by high flow, non-rebreathing face mask $(70-80 \%$ fractional inspired oxygen), or $100 \%$ oxygen if the patient needs intubation, for 4-6 hours. I am unaware of anyone who treats acute poisoning with $100 \%$ oxygen for $2-3$ days, apart from Scheinkestel et al in their trial. No trial has shown that inhalation of normobaric oxygen improves outcome in carbon monoxide poisoning or the optimal duration of this treatment.

Since the neuropsychological and disability rate in Scheinkestel et al's control group was relatively high and similar to that seen by others, $^{3-7}$ it is unclear if giving $100 \%$ normobaric oxygen for three days has any advantage over giving 70-100\% oxygen for only a few hours. Since optimal oxygen treatment is poorly defined, I disagree with Tighe that three days of treatment is indicated for acute carbon monoxide poisoning.

Tighe takes exception to the delay to hyperbaric oxygen treatment, and Scheinkestel et al have provided illustrative additional information. I agree with Tighe that transportation to a hyperbaric oxygen chamber can present problems. I disagree with him that a multicentre prospective randomised controlled trial of hyperbaric oxygen would be unethical. On the basis of existing trials, ${ }^{1{ }^{137}}$ such a trial would be ethical because present evidence is conflicting. Because the evidence is conflicting I see no reason why hyperbaric oxygen treatment for acute carbon monoxide poisoning should be abandoned.

The NHS and the Health Care Financing Administration in the United States might review their funding strategies for hyperbaric oxygen treatment in acute carbon monoxide poisoning, but the cost of hospital admission for three days (to provide $100 \%$ normobaric oxygen) is also considerable and needs to be considered. Regardless of the treatment of carbon monoxide poisoning, increased societal awareness and prevention of carbon monoxide poisoning remain critically important.

Lindell K Weaver medical director, hyperbaric medicine

LDS Hospital, Eighth Avenue and C Street, Salt Lake City, UT 84143, USA

1 Scheinkestel CD, Bailey M, Myles PS, Jones K, Cooper DJ, Millar IL, et al. Hyperbaric or normobaric oxygen for acute carbon monoxide poisoning: a randomized controlled clinical trial [see comments]. Med J Aust 1999;170:203-10. 2 Hopkins RO, Weaver LK, Churchill S. Attempted suicide in carbon monoxide $(\mathrm{CO})$ poisoning does not influence long-term neuro-psychological (npt) outcome: program and abstracts. Undersea Hyperb Med 1999;26(suppl):51.

3 Thom SR, Taber RI Mendiguren II Clark JM, Hardy KR,

Fis SR, Fisher AB. Delayed neuropsychologic sequelae after 
hyperbaric oxygen. Ann Emerg Med 1995;25:474-80.

4 Raphael JC, Elkharrat D, Jars-Guincestre MC. Trial of normobaric and hyperbaric oxygen for acute carbon monoxde intoxication. Lancet 1989;ii:414-9.

5 Smith JS, Brandon S. Morbidity from acute carbon monoxide poisoning at three-year follow-up. $B M J$ 1973;i:318-21

6 Weaver LK, Hopkins RO, Howe S, Larson-Lohr V, Churchill, S. Outcome at 6 and 12 months following acute CO poisoning. Undersea Hyperb Med 1996;23(suppl):9-10.

7 Ducasse JL, Celsis P. Marc-Vergnes JP. Non-comatose patients with acute carbon monoxide poisoning: hyperbaric or normobaric oxygenation? Undersea Hyperb Med 1995;22:9-15.

\section{Investigations of doctors by General Medical Council}

\section{Procedure for consent still leaves much to} be desired

EDITOR-As a patient advocate who attended the entire hearing of the case against gynaecologist Ian Fergusson, I was disappointed at the complacency inherent in the panel's assertion that "fortunately" the consent procedure has "been improved" in the eight years since the incident.

Some hospitals have undoubtedly made great strides. Patients consistently report, however, that the procedure adopted in many hospitals leading to their signature on a totally unacceptable consent form still leaves a lot to be desired. They still do not have an opportunity to identify in writing any procedure to which they object, and they are still expected to sign that everything has been explained, despite the absence of supporting written evidence.

Though the General Medical Council has produced excellent guidelines, ${ }^{2}$ their application is a matter of local whim. A similar situation applies to guidelines on consent to anaesthesia. ${ }^{3}$ Consent to anaesthesia and surgery is a matter of basic human rights. It should not be a matter of individual hospital policy.

Unless new regulations enforceable in all trusts are evolved by patient representatives working in partnership with the profession and the government, we are likely to see more such cases, in which there are no winners, only losers. Public trust and confidence in medical practice will continue to suffer unnecessarily, to the detriment of patients and doctors alike.

Roger M Goss director (and lay member, BM) editorial board)

Patient Concern, PO Box 23732, London SW5 9FY rogerconcern@hotmail.com

1 Dyer D. Gynaecologist cleared in hysterectomy case. $B M$ 2000;320:535. (26 February.)

2 General Medical Council. Seeking patients'consent:the ethical considerations. London: GMC, 1998.

3 Association of Anaesthetists of Great Britain and Ireland. Information and consent for anaesthesia. London: AAGBI, 1999.

\section{Expert witnesses who are out of step should be named and shamed}

EDITOR-Like, I suspect, many other surgeons, I was delighted to learn that the General Medical Council found Ian Fergusson not guilty of serious professional misconduct. ${ }^{1}$ I appreciate that the council must investigate a surgeon who has several complaints against him relating to his surgery. I have difficulty, though, with the concept of investigation related to a single case in what I suspect is an otherwise blameless career of a doctor who has done much good during his professional life.

The issue that causes me much greater concern, however, is that for the GMC to hold this hearing at least one gynaecologist must have expressed to it, both in writing and in evidence, that Mr Fergusson's actions were indeed those of a man who should receive the strongest condemnation that our profession has to offer. Clearly, that gynaecologist is himself or herself seriously incorrect in holding this view. The charge of serious professional misconduct is so grave that that gynaecologist must have been in absolutely no doubt that Mr Fergusson had behaved in so extreme a manner. Yet that gynaecologist was wrong.

What, therefore, is to become of the gynaecologist whose advice to the counci was so erroneous? In court, if an expert witness expresses an opinion that is so far off the mark there is an increasing tendency for such opinions to be recorded in law reports. Such naming and shaming may have the effect of limiting future instructions for that expert. I would like to be reassured that the GMC will follow such an approach.

G J Jarvis consultant obstetrician and gynaecologist BUPA Hospital, Leeds LS8 1NT

\section{Dyer D. Gynaecologist cleared in hysterectomy case. $B M$ 2000;320:535. (26 February.)}

\section{Risk assessment of left ventricular systolic dysfunction in primary care}

\section{Drug treatment might be contaminating factor}

EDITOR-The burden on echocardiography services could indeed be reduced if natriuretic peptide concentrations plus electrocardiography were used as screening tools for left ventricular systolic dysfunction. ${ }^{1}$ Nielsen et al's paper confirms the high negative predictive value of these tests. Concomitant drug treatment could, however, be a crucial contaminating factor.

The use of natriuretic peptides to diagnose left ventricular dysfunction in patients who are already taking cardiac drugs deserves particular attention. Diuretics, digoxin, and angiotensin converting enzyme inhibitors reduce natriuretic peptide concentrations. ${ }^{2}$ Especially important is the fact that frusemide (furosemide) reduces these concentrations ${ }^{3}$ but will have virtually no effect on an echocardiogram; it will not alter left ventricular dysfunction. Obviously, therefore, frusemide could severely distort the relation between natriuretic peptides and the echo finding of left ventricular systolic dysfunction.

The predictive value of natriuretic peptides could conceivably be considerably affected by the presence of frusemide and other cardiac drugs. This could explain why the sensitivity of natriuretic peptides is low in Nielsen et al's study. No study has yet addressed the usefulness of natriuretic peptides in identifying left ventricular dysfunction before diuretics have been prescribed, which is obviously the real clinical question. When general practitioners want to know if left ventricular dysfunction is the cause of breathlessness in a patient they want to be able to take a blood sample to measure the natriuretic peptide concentration there and then (and before prescribing a diuretic). They can then prescribe a diuretic as a failsafe mechanism pending the result of the test. The opposite may occur with $\beta$ blockers as recent data suggest that they increase brain natriuretic peptide while having a beneficial effect on left ventricular dilatation. ${ }^{4}$

Cardiac drugs could therefore be a major contaminating factor in the use of natriuretic peptides to diagnose left ventricular dysfunction. An interesting question now arises from Nielsen et al's work: were there any differences in the predictive value of atrial natriuretic peptide concentration, clinical features, findings on electrocardiography, and heart rate and blood pressure between those patients taking cardiac drugs and those patients not taking any treatment in this study?

Robert Kelly research fellow

Allan D Struthers professor of clinical pharmacology Department of Clinical Pharmacology, Ninewells Hospital, Dundee DD1 9SY

I Nielsen OW, Hansen JF, Hilden J, Larsen CT, Svanegard J. Risk assessment of left ventricular systolic dysfun primary care. BMJ 2000;320:220-4. (22 January.)

Prirect Murdoch DR, McDonagh TA, Byrne J, Blue L, Farmer R, Morton JJ, et al. Titration of vasodilator therapy in chronic heart fallue according to plasma 138 ; $1126-32$.

3 Northridge DB, Newby DE, Rooney E, Norrie J, Dargie HJ. Northridge DB, Newby DE, Rooney E, Norrie J, Dargie HJ. Comparison of the short-term effects of candoxatril, an orally active neutral endopeptidase inhibitor, and frusemide in the treatment of patients with chronic heart failure. Am Heart J 1999;138:1149-57.

4 RESOLVD Investigators. Effects of metoprolol CR in patients with ischemic and dilated cardiomyopathy. Circulation 2000;101:378-84.

\section{Authors' reply}

EDITOR-Kelly and Struthers make a point that applies in many branches of medical diagnosis - namely, that drug treatment may influence not only subjective symptoms but also biological disease markers. If a drug breaks into a complicated system of feedback regulations, as is the case with natriuretic peptides, the net effect is unpredictable and must be assessed empirically. The question whether cardiac medication influences the predictive power of natriuretic peptides in subjects with minor symptoms is therefore an important one.

In our study we applied the tests on a broad spectrum of suspected heart patients from general practice. We did not consider treatment in the analysis because diuretic treatment is based on subjective and arbitrary decisions, because a subdivision of the small cohort would increase the risk of making type II errors, and because we only had limited space for publication. 
Risk assessment of left ventricular dysfunction in patients according to treatment with diuretics (loop diuretic or angiotensin converting enzyme inhibitor plus other diuretic)

Untreated $(n=95)$

Treated $(\mathrm{n}=25)$

\begin{tabular}{|c|c|c|c|c|c|c|c|}
\hline \multirow[b]{3}{*}{ Type of test } & \multirow{2}{*}{\multicolumn{3}{|c|}{ Left ventricular systolic dysfunction }} & \multirow{2}{*}{\multicolumn{3}{|c|}{ Left ventricular systolic dysfunction }} & \multirow{3}{*}{$\begin{array}{c}\text { Pooled } \\
\text { odds } \\
\text { ratio }\end{array}$} \\
\hline & & & & & & & \\
\hline & Yes & No & Odds ratio & Yes & No & Odds ratio & \\
\hline \multicolumn{8}{|c|}{ Abnormal ECG (as in paper): } \\
\hline Yes & 7 & 39 & $\infty$ & 6 & 9 & 6 & 16 \\
\hline No & 0 & 49 & & 1 & 9 & & \\
\hline \multicolumn{8}{|c|}{$\mathrm{N}$-terminal atrial natriuretic peptide $(\mathrm{nmol} / \mathrm{l})$ : } \\
\hline$>0.8$ & 2 & 5 & 6 & 4 & 4 & 7 & 9 \\
\hline $0.5-0.8$ & 4 & 24 & & 0 & 7 & & \\
\hline$<0.5$ & 1 & 53 & 11 & 2 & 7 & 1 & 5 \\
\hline \multicolumn{8}{|c|}{ Heart rate > diastolic blood pressure: } \\
\hline Yes & 4 & 12 & 8 & 4 & 2 & 11 & 9 \\
\hline No & 3 & 75 & & 3 & 16 & & \\
\hline
\end{tabular}

Despite these limitations, and prompted by the query by Kelly and Struthers, we have made a renewed analysis of those 25 patients treated with either loop diuretics or an angiotensin converting enzyme inhibitor in combination with another diuretic, comparing them with 95 patients without this treatment (table). Missing values and pacemaker patients were excluded. Totals are thus different from those of the original table 3 . The prevalences of left ventricular systolic dysfunction were $30 \%$ and $7 \%$ respectively.

This difference in prevalence of systolic dysfunction makes it hard to compare test behaviour in the two groups. It appears from the table, however, that electrocardiographic anomaly gives full sensitivity (scoring no false negatives), whereas the predictor heart rate > diastolic blood pressure has an unchanged performance. As Kelly and Struthers may have expected, the natriuretic peptide improves its discriminative power in the untreated patient group, especially if the cut-off point is lowered. The lower cut-off point, however, weakens the predictive positive value of the test.

In conclusion, there seem to be fewer false negatives among the untreated patients by several criteria. The table therefore suggests that when testing is restricted to untreated patients one can more safely rule out left ventricular systolic dysfunction by normal electrocardiographic results and a normal natriuretic peptide concentration. The table also suggests that echocardiography should always be considered if a loop diuretic is required to control symptoms. Since this subanalysis is based on a small patient sample, we plan to undertake a more careful analysis in a larger cohort, where potential confounders other than drug treatment will also be considered.

Olav Wendelboe Nielsen research registrar own@dadlnet.dk

Cardiovascular Department Y, Copenhagen University Hospital, 2400 Bispebjerg, Denmark

Jørgen Hilden lecturer

Department of Biostatistics, Copenhagen

University, 2200 Panum Institute, Denmark

Jens Svanegaard chief physician

Department of Cardiovascular Medicine, Haderslev Hospital, Denmark

Jørgen Fischer Hansen chief consultant Cardiovascular Department Y, Copenhagen

University Hospital, 2400 Bispebjerg

\section{Ethnic minorities have specific needs with regard to cardiovascular risk} high risk of coronary heart disease is vital for preventive clinical care. ${ }^{12}$ Robson et al state that a reduction of absolute cardiovascular risk in the tenth of the population with coronary risk $\geqslant 30 \%$ is likely to be cost beneficial. ${ }^{3}$ South Asians and Afro-Caribbeans in the United Kingdom are at increased risk of coronary heart disease and stroke, respectively, compared with people of European ethnicity. Most of the United Kingdom populations studied for assessment of cardiovascular risk have not, however, been stratified by ethnic group, and little research has been conducted into factors affecting uptake of preventive care in such patients.

We recently performed a pilot study of assessment of cardiovascular risk factors in south Asian and Afro-Caribbean patients aged 16-79 attending one south London practice. ${ }^{4}$ We found that half had at least two risk factors for cardiovascular disease. Women were less likely than men to be smokers (relative risk 0.4; 95\% confidence interval 0.2 to 0.8 ) but more likely to take little or no exercise $(1.7 ; 1.1$ to 2.5$)$. Focus groups suggested that barriers to effective health promotion included lack of awareness of risk, language difficulties, and cultural and lifestyle differences.

Motivational state and lack of perceived or actual risk may also cause delays in seeking medical help even after risk factors have been identified. Another London based study found that hypertensive patients of Afro-Caribbean ethnicity were less likely to use antihypertensive drugs than were patients of European ethnicity. ${ }^{5}$ General practitioners and primary care groups determining local policies for coronary disease prevention need to be aware of the specific needs of ethnic minority groups.

Mariam Molokhia clinical research fellow Epidemiology Unit, London School of Hygiene and Tropical Medicine, London WC1E 7HT Mariam.molokhia@lshtm.ac.uk

Pippa Oakeshott senior lecturer Department of General Practice, St George's Hospital Medical School, London SW17 0RE
EDITOR-The identification of patients at
1 Wood D, Durrington P, Poulter N, McInnes GT, Rees A Wray R. Joint British recommendations on prevention of coronary heart disease in clinical practice. Heart 1998;80:1-29S

2 Ramsay LE, Williams B, Johnston GD, MacGregor L, Potter JF, Poulter NR, et al. Guidelines for management of hypertension: report of the third working party of the British Hypertension Society. J Hum Hypertens 1999;13:569-92.

3 Robson J, Boomla K, Hart B, Feder G. Estimating cardiovascular risk for primary prevention: outstanding questions for primary care. BMJ 2000;320:702-4. (11 March.)

4 Molokhia M, Oakeshott P. A pilot study of cardiovascular Molokhia M, Oakeshott P. A pilot study of cardiovascular risk assessment in Afro-Caribbean patients attending an 5 .

5 Morgan M. The significance of ethnicity for health promotion. patients use of antihypertensive drugs in inne London. Int J Epidemiol 1995;24(suppl 1):S79-84.

\section{Writing a book-a personal experience}

EDITOR-Albert's article on how to become a book author struck a chord with me, as I have been through the experience he describes. ${ }^{1}$ I was talked into writing a textbook after meeting a publisher at a party, and did so largely without thinking about why I was doing it. My social life suffered hugely while I spent three years trying to write the book as well as do my day job.

Would I do it again? I'm not sure. It certainly gained valuable points for my resumé, and it probably helped my career immensely. Financially, it was a disaster. Although I made some money out of the book, students these days can rarely afford to buy textbooks, so despite having had excellent reviews it has not sold well and will probably soon be out of print. Working out how much I have earned in royalties compared with how much time I spent on the book, my hourly rate was probably no more than about $50 \mathrm{p}$

The one piece of advice I would add to Albert's eminently sensible suggestions would be to join the Society of Authors at an early stage. The society provides wonderful support for authors, including vetting publishing contracts. It can be found at www.writers.org.uk/society.

Adam Jacobs director

Dianthus Medical, Mitcham, Surrey CR4 3BA ajacobs@dianthus.co.uk

1 Albert T. How to become a book author [career focus]. BMJ 2000;320:(classified section 18 Mar):2-3.

\section{Career development in public health}

\section{Doctors should lead public health departments}

Editor-McPherson's letter exemplifies the problem inherent in the demedicalisation of public health medicine. ${ }^{1}$ Of course the quality of the training available to non-medical public health workers needs to be improved. So do career and pay structures to recruit and retain those highly skilled individuals from a variety of specialties who make up the public health team, particularly public health infection control nurses, who are in extremely short supply.

A broad range of skills is required to make public health teams function 
properly in the real world. Different members of the team bring different knowledge and skills, and these are not readily interchangeable.

But McPherson trivialises what medical training is. A medical degree is much more than studying the illness of individuals. Most courses are designed to enable prospective doctors to do their jobs, which means they will deal compassionately with sick and well people, understand and treat illness as a social and individual phenomenon, and work with others in teams. The breadth of the scientific and social compass of medical training mirrors the range of additional skills needed if we are to be effective improvers of the public's health. Doctors who work in public health build on this foundation and develop sufficient competence in most of the skills needed in any public health team either to lead specific areas of work or to understand what others will contribute. No other discipline in the team can do this, but this kind of understanding is essential for its proper leadership. This is why we believe that doctors should lead public health departments.

Sarah Taylor chairman

Charles Saunders chairman, negotiating team BMA Committee for Public Health Medicine and Community Health, British Medical Association, London WC1H 9JR

McPherson K. Removing barriers to career development in public health. BMJ 2000;320:448. (12 February.)

\section{Career choice in public health should be} less restricted

EDITOR-McPherson supports careers in public health without a glass ceiling and promises availability of excellence in training in public health for those without a medical degree. ${ }^{1}$ Why is formal training in public health necessary for a career in public health? The tools that a director of public health needs in order to manage the health of the population are, in principle, no different from those required by a director of social services, a senior civil servant, or the chief executive of a public body.

The restrictive career choice in public health has, like all restrictive practices, distorted and skewed public health in the country. Practitioners in public health medicine would find it difficult-looking at death rates from heart disease and cancer-to justify the monopoly of their specialty in improving the health of the population. The dismal picture may not be their fault, but it does require alternative solutions. The United Kingdom compares unfavourably with other European countries, where there is less emphasis on the medically oriented practice of public health.

Removing the glass ceiling will attract candidates of the highest calibre, including doctors. An unfettered pay structure outside the NHS pay scale will reward achievement. As McPherson states, the excellently medically trained public health doctors have nothing to fear from competition.

Change is painful. The BMA has a duty to protect the interests of its members. It should not do so from a narrow perspective. Saving Lives: Our Healthier Nation presents an opportunity to improve dramatically the health of the population. ${ }^{2}$ We should seize this opportunity with both hands.

Surinder Bakhshi consultant in communicable disease control

Birmingham Health Authority, Birmingham B16 9RG

McPherson K. Removing barriers to career developmen in public health. $B M J$ 2000;320:448. (12 February.)

Secretary of State for Health. Saving lives: our healthier nation. London: Stationery Office, 1999. (Cm 4386.)

\section{Allocating prescribing budgets}

Limitations of formula should have been stated more clearly

EDIToR-Rice et al present what they describe as a "needs based" formula for allocating prescribing budgets. ${ }^{1}$ This seems an improvement on the ASTRO-PU (age, sex, and temporary resident originated prescribing unit), which it replaces, but in view of its crucial impact on the resources available to general practitioners and their patients its limitations should be stated more clearly.

Despite its title, the formula does not assess need directly but relies on data from the national census to generate proxy measures. The association between these measures and prescribing costs "explains" observed variation in these costs only in the narrow statistical sense of the word. Bains and Parry, ${ }^{2}$ and Majeed $^{3}$ point out further important limitations.

These criticisms are of more than academic importance. The formula is "needs based" only in a vague and general sense, but despite its manifold weaknesses there is a danger that NHS organisations will use it as if it were an adequate basis for budget setting and monitoring prescribing performance. The patients whose access to treatment will be thus determined and rationed will not be proxies.

Primary care groups have the difficult task of salvaging something from this minefield. If we wish to explain variations in prescribing in the full sense of the word and if we are serious about the pursuit of equity and quality, we have a great deal of work to do. Several actions spring to mind.

Firstly, computerisation gives us the means to collect detailed morbidity data at practice level. This will allow us to test the formula for allocating prescribing budgets against real measures of need and, if necessary, make allowances in practice based budgets.

Secondly, by combining prescribing and morbidity data, and auditing standards of care, we can ensure that measures of quality are built into our incentive schemes. We will also gain considerably in our understanding of the many causes of variations in prescribing costs.

Thirdly, we might consider foregoing the right to keep savings from our practice prescribing budgets. In a cash starved NHS, large handouts for cheap prescribing should be seen as the occasion for red faces rather an opportunity for red carpets.

C A Ryle clinical governance lead, East Hants Primary Care Group

Compton, Chichester, West Sussex PO18 9NT

1 Rice N, Dixon P, Lloyd DCEF, Roberts D. Derivation of a needs based capitation formula for allocating prescribing budgets to health authorities and primary care groups in England: regression analysis. BMJ 2000;320:284-8. (29 January.)

2 Bains DL, Parry DJ. Analysis of the ability of the new needs adjustment formula to improve the setting of weighted capitation prescribing budgets in English general practice BMJ 2000;320:288-90. (29 January.)

3 Majeed M. New formula for GP prescribing budgets. BMJ 200;320:266. (29 January.)

\section{All prescribers in primary care groups} need to collaborate

EDITOR-Equity is a central concern of primary care groups, which are responsible for allocating prescribing budgets to practices. Unfortunately, existing weighted capitation formulas can produce anomalies at practice level. Primary care groups face having to make subjective adjustments that are neither transparent nor acceptable. The promise of a new, intuitively plausible formula, ${ }^{1}$ especially one that is at last based on registered practice populations, will therefore, as Majeed warns, ${ }^{2}$ be attractive to primary care groups.

However, primary care groups should not use Rice et al's formula, for at least three reasons. Firstly, it uses the fatally flawed method of trying to predict the needs of practice populations from attributed data derived geographically: the ecological fallacy.

Secondly, applying existing formulas at practice level has long been controversial. Rice et al do not propose their formula for calculating practice prescribing budgets.

Thirdly, the inherent weaknesses of using existing census data are readily admitted by health economists. ${ }^{4}$ Why then continue to conjure formulas from poor data of doubtful relevance?

Using registered practice populations instead of attributed census counts is a breakthrough, but it is not sufficient on its own. Clinical research into measures of healthcare need should be funded and promoted by primary care groups. Indeed, information on the back of prescription forms has already been used by Lloyd et al for a low income index of deprivation. ${ }^{5}$ This is immeasurably more plausible than using old census data on the percentage of dependants in no carer households.

Years of health economics and statistics have produced practice budgets that are like rainbows. They have shape and colour but do not touch the ground. What we know about best, on the ground in general practice, is prescribing for individual patients. I prefer a bottom up approach to budget setting, driven by collaboration among all the prescribers in the primary care group. As clinical prescribing data are increasingly computerised, audit can become more extensive and the quality of care be assessed in greater detail, including cost effectiveness. We should aim to set prescribing budgets for our practices on summated data about individual patients and 
their care. Meanwhile, cost growth comparisons among practices will alert the primary care group to unequal use of the budget.

Perhaps the doctors and nurses charged with promoting equity in the "New NHS" are best placed to assess whether practice prescribing budget calculations are "intuitively plausible," at least until rainbows touch the ground.

Tony Thick vice chair

Newcastle North Primary Care Group, Newcastle upon Tyne NE1 8BG

1 Rice N, Dixon P, Lloyd DCEF, Roberts D. Derivation of a needs based capitation formula for allocating prescribin budsets to health authorities and primary care groups in (a) England: regression analysis. BMJ 2000,320:284-8. (29 January.

Majeed A. New formula for GP prescribing budgets. $B M J$ 2000:320:266. (29 January)

3 Sheldon TA, Smith P, Borowitz M, Martin S, Carr-Hill R. Attempts at deriving a formula for setting general practitioner fundholding budgets. BMJ 1994;309:1059-64. 4 Sheldon TA, Smith GD, Bevan G. Weighting in the dark: resource allocation in the new NHS. BMJ 1993;306:835-9. 5 Lloyd DCEF, Harris CM, Clucas DW. Low income scheme index: a new deprivation scale based on prescribing in general practice. $B M J$ 1995;310:165-9.

\section{Lord, protect me from my friends}

\section{Public needs to be educated}

EDITOR-I am appalled by Farrell's attitude in his Soundings column. ${ }^{1}$ I question whether a doctor who prescribes antibiotics for flu for the purpose of "sporting one-upmanship" and "tactical gratification," in spite of "academically impeccable advice" given by his partner, and for paediatric otitis media to "keep the parents happy" should be prescribing at all, let alone be allowed to air his views in a serious medical journal.

This sort of attitude is undoing all the work done by those of us trying to educate the public about the difference between viral and bacterial infections and the role of antibiotics in order to stem the growing tide of bacterial resistance. His patients will no doubt turn up to their local accident and emergency department expecting to be treated with antibiotics for minor ailments and may well become agitated or aggressive if refused.

Many times I have heard the line, "But my GP gives me antibiotics when I get this," and have had to stand my ground in the face of significant verbal abuse in some cases. In this respect, Farrell had succeeded with his "screw them before they screw you" attitude because the correct practice of the hospital is seen by the patient as doing nothing and being uncaring, thus antagonising the already strained relationship between general practitioners and hospital doctors when in truth we should be working together for the benefit of our patients. My sympathy goes to Farrell's partner, who no doubt gets tarred with the same brush in discussions at the local accident and emergency department, and I would end with a prayer for him and the rest of us-Lord, protect us from doctors like Farrell.

Ian Frankel accident and emergency staff grade Watford General Hospital, Watford WD1 8HB
1 Farrell L. Lord, protect me from my friends. BMJ 2000;320:523. (19 February.)

\section{Also my experience}

EdITOR-Farrell's piece ${ }^{1}$ accurately describes my practice over 32 years with largely the same partners.

The description is accurate almost down to the last period.

Colin Mackenzie retired family doctor

11 Westwood Road, Santa Cruz, CA 95060-1444, USA

colin@mackenzies-chocolates.com

1 Farrell L. Lord, protect me from my friends. $B M$ J 2000;320:523. (19 February.)

\section{Author's reply}

EDITOR-I remember my time in casualty very well, and I could sure sing a few bars of Frankel's frustrated song, but "medical humour helps us bear the unbearable."1 It's not healthy to be excessively sensitive; the Great Irish Famine was all the fault of the English, but that was a long time ago and I've kinda gotten over it by now.

There is a certain realpolitik to consider. Casualty attenders are usually one-offs; in primary care repeat attenders are common, and some unwritten axioms apply. A sick child seen for the second time should be considered for antibiotics, one seen for the third time perhaps requires admission-and see how many of them did not receive antibiotics.

But I do regret taking too lightly what is undoubtedly a serious subject. "Antibiotics are like the F-words; used sparingly they are have no effect except to indicate that the user is a foul-mouthed git."

Mea culpa, we general practitioners are imperfect creatures, yet: "Our weakness is our greatest strength; we understand human frailty because we ourselves are human and weak"; a sinner's prayers are often the best.

The term screw, I emphasise, was purely metaphorical.

Liam Farrell general practitioner

Crossmaglen Health Centre, Crossmaglen, County Armagh BT25 9HD

1 Farrell L. No laughing matter. BMJ 1995;310:1415 2 Farrell L. No cure for the 'flu. Lancet 1998;351:92 3 Farrell L. Star Trekking. Br J Gen Pract 2000;50:86.

\section{Sexual health through leadership and "sanuk" in Thailand}

EDITOR-In their letters Bellis and Ashton, and van den Akker, comment on the role of the media in supporting the cultural change necessary to promote responsible sexua behaviour. ${ }^{12}$ Education and service provision as advocated by Yamey are of limited value, ${ }^{3}$ with much of the target group being resistant to, or outside the reach of, forma education and public health services. The Asian Centre for Population and Community Development in Thailand, under the leadership of Mechai Viravadya (a Thai senator), provides a practical example of success in this area.

The Thai attitude to sex is typically Asian, discreet and modest (not to be confused with Western mythology regarding concubinage and the small but notorious tourist oriented sex industry). The centre has been remarkably successful in promoting use of condoms by appealing to the Thai sense of "sanuk" or fun. While primarily seeking to address overpopulation, deprivation, and child mortality in rural districts, the centre has also succeeded in other ways: from being an AIDS hotspot, Thailand is now in the World Health Organization's "decrease or no growth" category.

The centre is a charity, and among its fundraising efforts is a chain of Cabbages and Condoms restaurants ("our food is guaranteed not to cause pregnancy"). So successful has the centre been that "Mechai" has become a slang word for condom. The centre runs an international training and education programme for healthcare workers, from which many developed countries could learn a lot.

If we follow the centre's example we must look beyond the attitudes and behav iour of young people and recognise the difficulties caused by the ambiguous attitudes (if not frank hypocrisy) of older peopleoften reflected in the most puritanical viewpoints contrasted with rather more liberal behaviour. If we admit (as young people already know) that sex is normal and fun, we should also recognise that it must be pursued responsibly and with respect for others, just like any other enjoyable but risky activity. This should be the focus of our education and public health activities and the message that the media is encouraged to endorse.

Perhaps one of our health policy makers could follow the example of Mechai Viravadya: we will recognise progress when a minister is prepared to appear on television juggling inflated condoms and we get a free packet of "Evettes" along with our afterdinner mints. Perhaps the issue will be whether or not we have a sufficiently well developed sense of sanuk to deal with this seriously.

Stephen McAndrew managing directo Healthcare Risk Resources International, London EC3M 5EA smcandrew@hrri.co.uk

1 Bellis MA, Ashton JR. The sexual health of boys and men. BMJ 2000;320:643. (4 March)

2 Van den Akker O. The sexual health of boys and men. BMJ 2000;320:643. (4 March.)

3 Yamey G. Sexual and reproductive health: what about boys and men? BMJ 1999;319:1315-6. (20 November.)

4 United Nations. United Nations human development report. Thailand: UN, 1997.

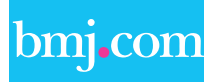

\section{Rapid responses}

Correspondence submitted electronically is available on our website 